\title{
EXPERIENCIA EDUCATIVA E IDENTIDADES \\ ÉTNICAS EN ESTUDIANTES UNIVERSITARIAS \\ INDÍGENAS DE LA REGIÓN METROPOLITANA
}

\section{Introducción}

La diversidad de los estudiantes que ingresan a la educación superior (ES), producto del aumento en las posibilidades de acceso de sectores que tradicionalmente no alcanzaban este nivel de formación, es un asunto que en los últimos años ha adquirido importancia creciente. Su problematización está vinculada a la discusión respecto de la equidad educativa y, por lo tanto, ha sido parte de las principales reformas que en ES se han impulsando en Estados Unidos, Europa y América Latina.

Como desafío, surge la necesidad de conocer las particularidades de los estudiantes, considerando una serie de dimensiones que atraviesan la diversidad estudiantil y que están marcadas por variables tales como clase, género, etnia, nacionalidad y las competencias de base, todas en estrecha relación con los procesos de aprendizaje y desarrollo que viven los sujetos (Sebastián y Scharager, 2007).

Uno de los grupos que ha logrado incrementar el acceso a la ES, y a las universidades en particular, es el conformado por hombres y mujeres indígenas, quienes, si bien han aumentado en este nivel educacional, mantienen una considerable brecha respecto de la población no indígena. Ésta es reflejo de las diferencias existentes en otros niveles educativos, en los cuales las tasas de analfabetismo y escolaridad básica y media siguen siendo menor para este grupo (MIDEPLAN, 2006). Cuando se analiza la variable de género al interior del mismo, se observa que el acceso de los varones es mayor al de las mujeres (Abarca y Zapata, 2007). 
Más allá de estos antecedentes de acceso, poco se sabe respecto de quiénes son estos estudiantes, sus demandas y expectativas, sus trayectorias educativas y universitarias, y los efectos que tiene su paso por la universidad en su desarrollo e inserción social.

Diversas evidencias muestran una relación particular entre experiencias educativas y construcción de identidades étnicas, debido a las características del proceso de inserción de la población indígena en la enseñanza superior, relacionado principalmente con la migración indígena a las urbes y la reciente incorporación de este grupo a dicho nivel de enseñanza (Bello et al., 1997). Asimismo, se evidencia la necesidad de indagar específicamente en la experiencia educativa de los jóvenes, hombres y mujeres, en la enseñanza superior, con el fin de conocer de forma más acabada la manera en que la experiencia educativa ocurre en contextos culturales diversos (Abarca y Zapata, 2007). Además, esta experiencia educativa y su proyección en la vida posuniversitaria podrían presentar especificidades de género, asociadas a la definición y relación específica de hombres y mujeres en nuestra sociedad (Bello et al., 1997; JUNAEB, 2008).

El vínculo entre ES y procesos de construcción identitaria en los y las estudiantes ha sido un tema problematizado con escasa profundidad, en especial cuando el foco está en las identidades o procesos de identificación étnica. De acuerdo con lo planteado por Matus (2004), quien ha investigado la situación de los estudiantes internacionales en universidades estadounidenses, las definiciones de las instituciones gubernamentales, así como las investigaciones referidas a estos sujetos, han levantado una comprensión estática y unitaria de la subjetividad.

Este artículo presenta los resultados de un estudio de caso que buscó indagar en la experiencia de las jóvenes universitarias indígenas de Chile, sector que, como se señaló, presenta los mayores indices de inequidad educativa. El propósito de la investigación fue conocer y comprender cómo se relaciona la experiencia educativa de universitarias indígenas de la Región Metropolitana con sus procesos 
178 ESTUDIANTES UNIVERSITARIAS INDÍGENAS DE LA REGIÓN METROPOLITANA Carolina Maillard, Gloria Ochoa, Andrea Valdivia

de construcción identitaria étnica. El estudio consideró a tres pueblos indígenas del país: aimara, mapuche y rapa nui.

El artículo ofrece, en primer lugar, algunos antecedentes de contexto para situar a las sujetos del estudio en relación con la caracterización de la población indígena y de las mujeres en términos educativos. Luego, se presenta el abordaje conceptual y metodológico del problema, para seguir con la presentación de los principales resultados y concluir con la discusión de ellos y de algunas reflexiones resultantes del estudio.

\section{Antecedentes generales sobre la población indígena}

En Chile se reconoce la existencia de los pueblos originarios o indígenas mapuche, aimara, rapa nui, atacameños, quechuas, collas, kawashkar, yámana y diaguita. Según el Censo de 2002, cerca de 700.000 personas afirmaron pertenecer a alguna de esas etnias (4,6\% de la población total), siendo los pueblos mapuche y aimara quienes tienen mayor representación, con un $87,3 \%$ y un $7 \%$ del total de la población indígena, respectivamente (INE y Programa Orígenes, 2005). Si bien los indígenas se ubican sobre todo en las zonas urbanas del país (65\%), en comparación con la población no indígena la proporción que vive en las zonas rurales es mayor.

Mientras que en el total de la población chilena la proporción de mujeres es levemente superior a la de los hombres (50,7\% y 49,3\%, respectivamente), en la población indígena esta situación se invierte: las mujeres representan el 49,6\% y los hombres el 50,5\%. En términos etarios destaca el alto porcentaje (52,3\%) de la población indígena entre los 0 y 29 años, mientras que en la población total este tramo representa el 50\%.

Al igual que en el resto de América Latina y otros países del mundo, los indígenas experimentan con especial rigor situaciones de pobreza y exclusión social (Bello y Rangel, 2000; Hopenhayn y Bello, 2001; Valenzuela, 2003). De esta manera, la pobreza en la población 
indígena alcanza el 19\%, con 5,7 puntos más que la media nacional (CASEN 2006).

\section{Educación y población indígena}

Las significativas diferencias sociales entre indígenas y no indígenas se observan también en el ámbito educativo. De acuerdo con la encuesta CASEN 2006, la brecha de alfabetismo entre la población indígena y no indígena es de 3,1 puntos porcentuales; mientras en la población indígena la tasa de analfabetismo llega al 6,8\%, en la no indígena es de un 3,7\%. Este indicador presenta diferencias relevantes entre hombres y mujeres, dado que el analfabetismo en las mujeres indígenas llega a un 10\%, mientras que entre los hombres indígenas es de un $6,5 \%^{1}$. Asimismo, mientras que en la población indígena urbana el analfabetismo alcanza un 3,1\%, en la rural se incrementa significativamente a un 10,3\%, siendo en el pueblo mapuche donde más se aprecia la disparidad entre analfabetismo urbano y rural. Igualmente, existe una brecha importante respecto a analfabetismo, género y ubicación geográfica, pues las mujeres indígenas urbanas analfabetas no superan el 6\%, mientras que las que habitan en zonas rurales alcanzan un $19 \%$. Por otro lado, se observa un menor promedio de años de escolaridad en la población indígena (10,3 años en no indígena frente a 8,7 años promedio en la población indígena).

En términos de cobertura, no aparecen diferencias estadísticamente significativas entre niños indígenas y no-indígenas en la escolaridad básica, al contrario de lo que se aprecia en las tasas de cobertura de la educación preescolar, media y superior, en las cuales se presentan diferencias vinculadas con el cruce de las variables de género y etnia. De este modo, las niñas indígenas asisten más a la educación preescolar en comparación con los niños indígenas, pero menos a la educación media y considerablemente menos a la ES.

1 Por tanto, en la población indígena existe una brecha de 3,5 puntos porcentuales entre analfabetismo de hombres y mujeres, siendo las últimas quienes presentan un mayor grado. En términos específicos, en la etnia aimara la diferencia es de 4,8 puntos porcentuales y en la mapuche es de 3,6 . 
180 ESTUDIANTES UNIVERSITARIAS INDÍGENAS DE LA REGIÓN METROPOLITANA Carolina Maillard, Gloria Ochoa, Andrea Valdivia

Mientras un 28\% de los hombres indígenas accede a la ES, la cifra disminuye en más de doce puntos porcentuales $(16,6 \%)$ para el caso de las mujeres² (Abarca y Zapata, 2007).

Entonces, son las mujeres indígenas quienes aún mantienen una posición de mayor desventaja en términos de equidad educativa y, en especial, en ES, ello a pesar del aumento en el acceso observado en los últimos años en la población indígena del país. Los aún escasos estudios relacionados señalan, además, que esta experiencia educativa y su proyección en la vida posuniversitaria podrían presentar especificidades de género, asociadas a la definición y relación específica de hombres y mujeres en nuestra sociedad (Bello et al., 1997; JUNAEB, 2008).

Como se ha señalado, el acceso de la población indígena, hombres y mujeres, a la ES corresponde a un proceso reciente y mantiene diferencias negativas respecto de la población no indígena. A su vez, las aspiraciones educativas han sido un factor de alto impacto en la migración, ya que la concreción de éstas se encuentra fuera de la comunidad originaria, lo que obliga a las personas a insertarse en modelos de vida distintos, en modelos de vida no-indígenas (Bello et al., 1997), en algunos casos.

Al igual que en otros grupos sociales, el acceso a la ES es para la población indígena un mecanismo de movilidad social ascendente (para el trabajo o para superar situaciones de pobreza). Sin embargo, en esta población adquiere cierta complejidad, ya que a las dificultades comunes con otros grupos se suman las asociadas a la discriminación (vivida por los padres o por los propios estudiantes). Como señala Bello, estas situaciones "constituyen un incentivo para buscar mecanismos de autoafirmación o de distanciamiento de su condición étnica: la ES y la formación profesional han sido formas efectivas para lograrlo".

2 A nivel nacional la cobertura de educación superior para las mujeres es de un 30\%. 
La incorporación tardía de los jóvenes indígenas a la ES ha llevado también a una relación conflictiva, tanto por el acceso dificultoso como por la compleja permanencia en este nivel del sistema. Por esto, es importante considerar el proceso que ha llevado a esta población a las instituciones de ES (Abarca y Zapata, 2007), que tiene su correlato en la relación entre los pueblos indígenas y la sociedad nacional.

A pesar de la ampliación de la cobertura, el problema de la inequidad al interior del sistema aún no está resuelto. Con relación a la permanencia en el sistema “...un $2 \%$ de la población indígena ha completado los estudios de nivel superior, mientras que el 6,9\% de la no indígena logró su finalización. Respecto de la ES incompleta, $2,5 \%$ de la población indígena se encuentra en esta condición frente al 5,6\% de los no indígenas" (CASEN, 2003; Población Indígena, 2005:52, en Abarca y Zapata, 2007:70).

Por otro lado, hay acuerdo en aceptar el progresivo aumento de la participación de las mujeres en la ES. También, las tasas de crecimiento de las matrículas nuevas en estas instituciones son más altas en el caso de las mujeres, sobre todo en universidades. Según José Miguel Salazar, la variación en las matrículas para primer año en universidades, entre 2002 y 2004, es de un 26\%, en el caso de las mujeres, y un $10 \%$ en los varones (Salazar, 2005).

Del total de matriculados en la ES hasta 2002, un 47,3\% corresponde a mujeres, mientras que un $52,7 \%$ a hombres. Si esto se compara con otras naciones de América Latina -Argentina (1998), Brasil (2000), Costa Rica (2002), Uruguay (1999) y Venezuela (1999)- la proporción de mujeres que acceden a la ES está muy por sobre la de los hombres (Papadópulos y Radakovich, 2006).

De acuerdo con las revisiones realizadas, se observa que el conocimiento sobre mujeres indígenas en educación terciaria es aún escaso. Salvo los antecedentes de la magnitud en el acceso y mantención en el sistema, poco se sabe respecto de quiénes son estas 
182 ESTUDIANTES UNIVERSITARIAS INDÍGENAS DE LA REGIÓN METROPOLITANA Carolina Maillard, Gloria Ochoa, Andrea Valdivia

estudiantes, sus demandas y expectativas, sus trayectorias educativas y universitarias, y los efectos que tiene su paso por la universidad en su desarrollo e inserción social. Por lo anterior, y considerando datos que muestran una relación positiva entre la autoidentificación étnica y la experiencia educativa en mujeres indígenas -ya que éstas potenciarían positivamente el que sus hijos e hijas alcancen mayores niveles de instrucción y, a su vez, tendrían un rol fundamental en la transmisión cultural, lo que ayudaría al proceso de valoración y autoidentificación étnica (JUNAEB, 2008)-, se optó porque los sujetos de investigación de este estudio fueran estudiantes mujeres de ES.

\section{Abordaje metodológico y teórico del estudio}

El diseño de investigación se perfiló como un estudio de caso. Se trabajó sobre la base de la experiencia de tres mujeres jóvenes indígenas, concebidas como sujetos históricos, culturales, sociales y discursivos, siendo interpretadas las particularidades de sus experiencias desde esta perspectiva y capturadas a partir de la narración que de ellas hacen las entrevistadas. Se estudió desde un punto de vista biográfico y narrativo, buscando que las mujeres -mediante el relato de sus experiencias y episodios significativos- configuraran sus procesos de autoidentificación y pertenencia étnica. De esa forma, los planos personal y cultural fueron abordados de manera simultánea y relacional, ya que el estudio de caso permite "reconstruir la creación personal de una historia, en diálogo con otras historias, y en el espacio sociocultural que les da sentido" (Aguirre, 1997: 204).

Los casos fueron tres jóvenes mujeres estudiantes universitarias: una aimara, una mapuche y una rapa nui, que cursaban segundo año de su respectiva carrera o más y que se autoidentificaban como indígenas. Además, residentes en la Región Metropolitana.

Asimismo, se optó por la realización de entrevistas en profundidad (por su pertinencia para la perspectiva biográfica y narrativa que se ha señalado), con un proceso de recogida de información no estructurado, en el cual la entrevista produce una 
"narración conversacional", una creación conjunta entre la entrevistada y el/la entrevistador/a (Aguirre, 1997). Durante las sesiones se trabajó en la reconstrucción de las experiencias de las estudiantes por medio de los relatos y la revisión de fotografías seleccionadas por ellas como una expresión de su reconstrucción biográfica.

Se utilizó un análisis de contenido de tipo categorial, dirigido por el marco conceptual que se presenta más adelante. La interpretación de los resultados consideró dimensiones socioculturales como: edad, contexto familiar y social, y trayectoria educativa y laboral de las entrevistadas y de los padres.

El marco conceptual que condujo el estudio se centró en las identidades étnicas y experiencias educativas. A continuación se presenta parte de esta discusión teórica.

\section{Identidades étnicas como procesos de identificación/ autoidentificación y pertenencia étnica}

La identidad como constructo teórico ha sido ampliamente discutido en las ciencias sociales, especialmente cuando se consideran las transformaciones culturales y sociales que ha traído consigo la globalización y sus implicancias en hombres y mujeres. De acuerdo con Larraín (2001), ésta ha afectado de tres formas los procesos de construcción identidataria: i) ha ampliado el espectro de "otros" con los cuales individuos, grupos y naciones se relacionan y respecto de los cuales se definen a sí mismos; ii) ha complejizado las posibilidades de formarse una visión unitaria del sí mismo y dar sentido al presente y los vínculos históricos, producto de las transformaciones temporales y espaciales de las relaciones sociales, y iii) habría favorecido procesos de desarraigo de identidades culturales ampliamente compartidas, alterando las categorías con las cuales los sujetos construyen sus identidades.

La última implicancia planteada por Larraín resulta relevante para efectos de este estudio, pues la globalización ha traído procesos 
184 ESTUDIANTES UNIVERSITARIAS INDÍGENAS DE LA REGIÓN METROPOLITANA Carolina Maillard, Gloria Ochoa, Andrea Valdivia

de "desarticulación y dislocación por medio de los cuales mucha gente cesa de verse a sí misma en términos de los contextos colectivos tradicionales que le daban un sentido de identidad, por ejemplo: profesión, clase, nacionalidad, religión, y comienza a verse en términos de otros contextos colectivos, por ejemplo, de género, etnias, sexualidad, equipos de fútbol, etc." (Larraín, 2001: 45).

El concepto de "etnia" hace referencia precisamente a aquellos elementos culturales vinculados con la identidad de los pueblos. Si bien hay diversos enfoques para abordar este concepto (Bello y Rangel, 2000), en este caso se propone aquel que concibe la etnia a partir de las perspectivas y prácticas culturales que distinguen a una comunidad dada de personas. Los miembros de los grupos étnicos se ven a sí mismos como culturalmente diferentes a otros grupos en la sociedad y son percibidos por los demás de igual manera (Valenzuela, 2003). De tal forma, hablamos de un corpus cultural asociado a dos elementos centrales: la pertenencia a determinado colectivo y la experiencia de identidad o, más bien, identificación de los sujetos de dicha colectividad.

La concepción contemporánea de las identidades se distancia de todo esencialismo que objetivaba "la identidad" en un estado y condición por medio de la posesión o no de una serie de atributos dados y preexistentes, y se posiciona desde un enfoque que las aborda desde su cualidad relacional, contingente y situacional. Tal como señala Arfuch (2005), la identidad en singular sólo puede ser vista como un "momento" identificatorio de los sujetos en un trayecto abierto, inacabado y responsivo (en diálogo) con el otro.

Esta perspectiva más constructivista de las identidades tiene una multiplicidad de matices según la radicalidad con que se asuma la contingencia de los procesos de identificación y autoidentificación, siendo las posturas posmodernas las que extreman quizás la deslocalización de las identidades, descentrando y fragmentando al sujeto. Frente a estas posiciones, también llamadas "blandas" por Brubaker y Cooper (2005), los autores, reconociendo los aportes 
que han hecho para avanzar en la comprensión de las identidades actuales, proponen cuidar la profundidad de su estudio por medio de la consideración de la identidad como un proceso y, a la vez, como un constructo teórico conformado por tres términos que dan cuenta de movimientos diversos pero relacionados: identificación y categorización; autocomprensión y localización social, y sentido de pertenencia ${ }^{3}$.

En este estudio se ha optado por abordar las identidades étnicas como identificación/autoidentificación y pertenencia étnica, ya que da cuenta de manera más pertinente de los procesos que se intenta abordar. La identificación, de sí mismo y del otro, es en relación con elementos y atributos que se creen propios del referente que etiqueta. En relación con la identificación está el sentido de pertenencia como el proceso más subjetivo de autocomprensión o elaboración de imágenes de sí mismo. El sentido de pertenencia permite dar cuenta del vínculo y sentimiento de conexión con el grupo que posee los atributos con los cuales se identifican los sujetos, con su espacialidad y prácticas culturales.

Con todo lo anterior, la identidad étnica, y más específicamente indígena, es concebida como un concepto y proceso dinámico, relacional y situado. Se "está siendo indígena" con relación a ese otro que no lo es, en momentos específicos y espacios determinados, lo que ocurrirá cuando esos otros, con los cuales se identifica o no, traigan a colación los atributos, categorías y elementos con que se define el "ser indígena". A partir de dicho escenario, los sujetos actúan y activan sus procesos más o menos implícitos de pertenencia étnica, configurando situacionalmente la autoidentificación. Esto, por cierto, no ocurre de manera aislada respecto de su devenir global: la autoidentificación étnica ocurre en diálogo (intersubjetivo y en conflicto) con sus otras adscripciones sociales: mujer, hombre, estudiante, trabajador, padre, hijo, entre otras. Tal como lo muestra el presente estudio, el cruce género y clase matizan significativamente las identidades étnicas.

3 Consignado por los autores como comunalidad, conexidad y grupalidad. 
186 ESTUDIANTES UNIVERSITARIAS INDÍGENAS DE LA REGIÓN METROPOLITANA Carolina Maillard, Gloria Ochoa, Andrea Valdivia

\section{Las identidades étnicas en diálogo con las trayectorias educativas y el contexto universitario}

Se cree que la trayectoria educativa marca de manera significativa los procesos de construcción de identidad, más aún cuando se sitúa en un contexto social y espacio vital de los sujetos como la etapa universitaria. Las experiencias que allí viven las y los sujetos desde sus múltiples identificaciones sociales (mujeres, estudiantes, madres, hijos, indígenas, migrantes, etc.) deben concebirse como parte de los procesos de formación académica y profesional, pues así como la trayectoria escolar, los contextos socioeconómicos actuales y las proyecciones y expectativas futuras (laborales y profesionales) son condicionantes del desempeño de los estudiantes, también lo son los escenarios relacionales en los que se juegan las prácticas educativas y en los cuales, por cierto, está el/la sujeto en su integridad y multiplicidad.

El momento y contexto especial que marca la experiencia universitaria se ha entendido con referencia a un proceso educativo mayor en la vida de los sujetos. Se han abordado los sentidos atribuidos a la educación (para qué, por qué y las fuentes desde donde construye el discurso acerca de la educación) porque conducen y orientan muchas de las decisiones y disposiciones en el contexto actual de formación universitaria. De manera relacionada, se ha concebido la experiencia universitaria de los sujetos en términos de condiciones de ingreso, motivaciones para la elección de la carrera, las imágenes de la universidad (como espacio social e institución académica), las experiencias de logro y fracaso, y las valoraciones de las políticas universitarias que apuntan a reconocer e identificar la diversidad cultural. Por último, también se deben considerar las expectativas de futuro, ya que, al igual que los sentidos respecto de la educación y quizá de manera más directa, conducen la trayectoria académica de los y las estudiantes universitarios. 


\section{Identidades étnicas y estudiantes mujeres de educación superior}

Antes de presentar los hallazgos referidos a las identidades étnicas en las sujetos de estudio, cabe considerar algunos elementos de los antecedentes familiares, sociales y culturales de las entrevistadas, que son significativos en sus historias de vida y aportan a la comprensión del problema investigado.

Dos (mapuche y aimara) de las tres jóvenes provienen de familias nucleares y biparentales, en las cuales el jefe de hogar es el padre y las madres dueñas de casa, a diferencia de la estudiante rapa nui quien sólo vive con su madre y abuela, siendo la primera la jefa de hogar. El nivel socioeconómico de los tres grupos familiares es medio bajo y bajo. Los niveles de escolaridad de los padres son diversos; mientras hay casos con estudios superiores (madre y padre de dos jóvenes), hay una madre con enseñanza básica incompleta y otros con enseñanza media completa.

Respecto del linaje indígena, la joven aimara tiene ascendencia por parte de padre y madre, mientras que las otras dos entrevistadas sólo presentan ascendencia indígena por parte del padre.

\section{La autoidentificación e imágenes de sí misma}

Cuando las jóvenes universitarias realizan su presentación personal recurren en primer lugar a categorías tales como nombre, edad y estudios. Una de ellas no menciona espontáneamente su ascendencia indígena, mientras que la estudiante rapa nui es la segunda categoría que utiliza luego del nombre, y marcando que es mestiza (mitad rapa nui, mitad continental); la joven aimara ocupa la etiqueta indígena desde su linaje y su condición de migrante. En este último caso, el "yo" de la presentación rápidamente pasará a un "nosotros" para narrar la trayectoria migratoria familiar, argumentando su autoidentificación étnica a través de dos elementos: la primera es la filiación -es decir, es aimara en tanto sus padres lo son- y la segunda los constantes viajes 
188 ESTUDIANTES UNIVERSITARIAS INDÍGENAS DE LA REGIÓN METROPOLITANA Carolina Maillard, Gloria Ochoa, Andrea Valdivia

al interior del norte grande para visitar (acompañar y colaborar en el trabajo del campo) a sus abuelos maternos.

El tema de la familia es transversal a las entrevistadas. En la presentación que hacen de ellas lo colocan en un lugar central; también, dos de ellas reconocen ser las primeras integrantes de la familia con estudios universitarios (en el caso de la estudiante rapa nui, será la primera profesional de la familia paterna).

Las tres estudiantes se presentan como personas responsables y con variadas ocupaciones (familiares, sociales, laborales y académicas); el grupo de baile, la iglesia, el trabajo y las acciones sociales son los ámbitos que las ocupan además de sus estudios. Se presentan como mujeres activas que, si bien asumen sus compromisos familiares, como colaborar con el cuidado de los hermanos menores, el orden y limpieza de la casa, entre otros, también aprecian y valoran su inserción en espacios públicos. En relación con ello, el tiempo es un tema que atraviesa sus relatos de presentación: narran sus rutinas cargadas de actividades y manifiestan la falta de tiempo para hacer otras cosas como, por ejemplo, dedicarse a conocer la cultura indígena o vincularse con organizaciones indígenas urbanas. Las estudiantes mapuche y rapa nui se reafirman en esa imagen, pareciendo disfrutar y necesitar de esa sensación de movimiento y activismo. En el caso de la estudiante aimara, esta imagen de alta demanda y falta de tiempo se vivencia actualmente con preocupación, pues su prioridad está en los estudios universitarios; constantemente se está diciendo a sí misma y a los otros que su foco es "sacar la carrera". Emerge aquí la imagen de una mujer moderna inserta en el mundo y espacio público, llena de responsabilidades y con la autoexigencia de ser exitosa en sus múltiples actividades.

Respecto de las imágenes que seleccionan para representar sus vidas, es importante destacar la relevancia que tienen aquellas asociadas a la trayectoria escolar, tanto propia como del resto de la familia. Las situaciones y momentos que evocan las fotografías confirman las imágenes de responsables y exitosas en el escenario escolar. 


\section{Autoidentificación e identificación étnica}

Como se señaló, es recurrente en las narraciones e imágenes de las jóvenes mostrar su pertenencia étnica. Ello se hace de modo más insistente en el caso de la estudiante mapuche cuando revisa sus fotografías: al considerar que no cuenta con el fenotipo tradicionalmente asociado con este pueblo, es enfática en señalar las diferencias entre su apariencia y la del resto de la familia mapuche. En este sentido, la estudiante rapa nui es la única que constantemente hace referencia a su condición étnica para su autoidentificación. Creemos que esto se debe, fundamentalmente, a que por aquella condición recibe la identificación y el reconocimiento de las personas con las cuales interactúa y, por cierto, lo "exótica" que resulta es valorado positivamente por los otros, al contrario de lo que sucede con las estudiantes mapuche y aimara, con las cuales, ya sea por el apellido o por la apariencia física, son identificadas como "indias o peruanas", existiendo una connotación despectiva frente a estas categorías. Principalmente las situaciones de reconocimiento negativo se dan en la etapa escolar y, en menor medida, en la universitaria actual. En todos los casos las entrevistadas explican los actos discriminatorios por la falta de información y formación de quienes los realizan.

\section{Elementos que caracterizan las culturas indígenas y su identificación con ellos}

Las entrevistadas rescatan elementos culturales similares de sus respectivas etnias. Sobresale el sentido de comunidad y familia, la fuerza, el ímpetu y la historia particular que tendrían éstas. Esos elementos darían un valor significativo a sus experiencias vitales y determinarían las diferencias con los no indígenas pues, al contrario de éstos, los indígenas conocerían sus raíces y las historias de sus antepasados. En el caso de los no indígenas, creen ellas, se les dificulta rastrear el propio origen y el de su familia; de este modo les resultaría casi imposible responder, por ejemplo, a la pregunta de dónde vengo. Esto último es enfatizado por las tres entrevistadas y su posibilidad de construirse desde ahí como sujetos con historia y 
190 ESTUDIANTES UNIVERSITARIAS INDÍGENAS DE LA REGIÓN METROPOLITANA Carolina Maillard, Gloria Ochoa, Andrea Valdivia

origen tan significativo es altamente valorada. Con estos elementos ellas se identifican y se acercan a un "nosotros" con distinta tonalidad y énfasis; el nosotros rapa nui es quizá el más enfático y explícito; mientras que el nosotros mapuche es más débil y no alcanza a ser un enunciado explícito en el discurso de la estudiante. En el caso de la joven aimara, adopta la mayoría de la veces la condicionalidad espacial y temporal: el nosotros de la comunidad de los abuelos; cuando hay un nosotros aimara en Santiago, éste evoca aquellos elementos que están en el espacio comunitario lejano.

La tierra que asienta la comunidad también es señalada como elemento distintivo de "lo indígena" por las jóvenes; sin embargo, la identificación personal con ella se torna más difusa pues no forma parte de su cotidianeidad. Las estudiantes aimara y rapa nui también señalan la lengua como un elemento característico de la cultura indígena, y su escaso conocimiento por parte de ambas es un punto de tensión y cuestionamiento respecto de su sentido de pertenencia y autoidentificación étnica.

Las relaciones de género son otra fuente con que caracterizan las culturas indígenas. Las estudiantes mapuche y rapa nui mencionan el machismo como un elemento distintivo. La primera considera que su familia mapuche es más machista que su familia materna, se distancia de esta característica valorándola negativamente, asociándola a una posición de subordinación de las mujeres en los grupos familiares y encasilladas a roles tradicionales. En el caso de la joven rapa nui, el machismo estaría en ambas familias (materna-continental y paternaindígena) y, a diferencia del caso anterior, ella se reconoce machista en el sentido de las pautas que marcan un ser femenino en la sociedad (labores del hogar, conductas impropias como "beber a la par de los hombres", entre otras), pero se distancia del machismo de los hombres rapa nui, como el padre o tíos, cuando se proyecta en pareja. En la narrativa de la joven aimara no aparecen destacadas las relaciones de género, salvo cuando se señala la patrilocalidad como un elemento distintivo de la cultura indígena. 
En su experiencia universitaria y en la proyección de la misma, la identificación y autoidentificación étnica de las jóvenes es decisiva para su definición, ya que es parte de sus expectativas vincular su desarrollo o su quehacer profesional con su cultura, ya sea a través de la incorporación de elementos culturales, como infraestructura mapuche a diseños arquitectónicos o medicina intercultural, o poniendo los propios conocimientos a disposición del desarrollo del respectivo pueblo.

\section{Sentido de pertenencia}

El contexto en el que se ubica la familia es determinante para el sentido de pertenencia étnica, pero no siempre se encuentra en una relación directa. Para la estudiante aimara resulta primordial para su sentido de pertenencia que sus padres hayan nacido y vivido parte de su vida en pueblos del interior de Arica e Iquique, donde la presencia aimara es altísima y se continúa con prácticas tradicionales, tales como el uso cotidiano de la lengua, fiestas, cuidado de ganado, cocina, entre otras. Lo anterior también conlleva que la situación de vida urbana implique dejar de lado aquellas prácticas, por considerar que ya fuera de contexto éstas pierden valor, por ejemplo, para el caso del uso de la lengua, pues no existirían espacios de interacción social para su uso significativo.

Una situación particular ocurre en el caso de la joven rapa nui, cuya ascendencia indígena es sólo por línea paterna, a lo que se suma que prácticamente no ha convivido con su padre (ella vive hace más de 15 años en Santiago, mientras que su padre no ha vivido en esta ciudad). Su mayor sentido de pertenencia con la isla está dado por el contacto permanente con familiares paternos radicados en la ciudad y dedicados a la música étnica. No obstante lo anterior, es altísima su identificación con Isla de Pascua y sus tradiciones.

Por otra parte, la estudiante mapuche manifiesta una tensión mayor con su sentido de pertenencia étnica, pues a la vez que se identifica con características psicológicas del padre, tales como el 
192 ESTUDIANTES UNIVERSITARIAS INDÍGENAS DE LA REGIÓN METROPOLITANA Carolina Maillard, Gloria Ochoa, Andrea Valdivia

mal genio que asocia a una especie de carácter mapuche (etiqueta identificatoria bien instalada en el sentido común en nuestro país), marca distancia de la identificación mapuche criticando esas características y resaltando un fenotipo más claro que el mapuche. Por otro lado, mientras escoge varias fotografías de su infancia en la comunidad de la familia paterna, se distancia de las prácticas y sentidos con que se identifica a lo mapuche. Es posible ver en sus relatos un ir y venir más conflictuado entre un "ellos", los mapuche (cuando se consignan esas características que cosifican la cultura, o cuando se trata de sus familiares de tez más oscura y que viven de la tierra), y un "nosotros", cuando se apela a experiencias más íntimas y cotidianas que la sitúan respecto de un otro que definitivamente no es mapuche (sus compañeros de universidad o colegio, por ejemplo).

La misma tensión entre un "nosotros" y un "ellos" está presente en las otras dos jóvenes, aunque con menor fuerza. Dependerá del contexto y situación interaccional la posición que asuman. Así, la estudiante rapa nui, si bien tiende a construir su narración con un enfático "nosotros los rapa nui", reconocerá que cuando va a la isla este sentimiento de pertenencia se cuestiona por la identificación que los otros (isleños) le confieren como distinta y por su menor dominio de las prácticas tradicionales. En el caso de la joven aimara, el nosotros indígena claramente está relacionado con el "allá" de la comunidad de sus abuelos.

Como se aprecia, la espacialidad es un tema significativo en los tres relatos. El "territorio" donde se asienta la comunidad indígena se connota como el lugar genuino donde se encontraría lo propiamente indígena.

La participación activa de las estudiantes aimara y mapuche en las iglesias evangélica pentecostal y católica, respectivamente, sugiere ser uno de los factores del distanciamiento hacia las prácticas tradicionales indígenas, sobre todo en el contexto urbano. 


\section{Experiencias educativas en los procesos de construcción identitaria}

\section{Sentido de la educación}

El sentido que las jóvenes atribuyen a la educación se encuentra principalmente relacionado con la posibilidad de mejorar sus condiciones de vida y las de sus respectivas familias. Destaca aquí la fuerte influencia paterna en dos de las entrevistadas. La figura e influencia del padre, así como su rol motivador y activo en la toma de decisión respecto al futuro educacional de las jóvenes, es preponderante en su historia educativa, principalmente en la decisión de continuar estudios superiores. Asimismo, la educación adquiere un fuerte sentido de estabilidad para la vida futura de las jóvenes y de sus familias.

Las principales razones en los esfuerzos paternos para incentivar la educación de las jóvenes tiene como núcleo dos sentidos principales, que luego ellas hacen parte de sus propios discursos respecto a la educación: la movilidad e integración social (personal y familiar), y un escudo contra la discriminación ("tienes que ser más y mejor que ellos"). Ambos sentidos configuran un cruce singular entre la condición de clase y la étnica, lo que complejiza y matiza la propia visión de la educación y las expectativas relacionadas con ella.

En el caso de la joven rapa nui, es importante señalar la distinción que establece entre la educación que se entrega en la isla y la que es impartida en el continente. Para ella, la educación allá es limitada, ya que sólo permite alcanzar un nivel técnico. Por lo tanto, para cumplir las expectativas de una educación distinta debe dejar la isla y estudiar en el continente. Para esta joven, los estudios superiores se vinculan también con tener una mirada diferente respecto de la educación y las expectativas laborales que el común de la población rapa nui; por lo tanto, sus expectativas y valoración de la formación universitaria son un elemento que la diferencia de lo que delimita como propio de la cultura rapa nui. Sin embargo, la joven pareciera 
194 ESTUDIANTES UNIVERSITARIAS INDÍGENAS DE LA REGIÓN METROPOLITANA Carolina Maillard, Gloria Ochoa, Andrea Valdivia

resituar esa distancia cultural enfocando su proyección profesional hacia el trabajo en el desarrollo social de los rapa nui en la isla.

De igual forma, la estudiante aimara también hace referencia a las desiguales posibilidades que hay entre Santiago y provincias, pues tiene claro que el traslado familiar a la capital permitió que toda la familia tuviera acceso a una mejor educación y mejores expectativas profesionales. La joven cree que estando en Iquique no habría entrado a la carrera de alto prestigio social que cursa actualmente (Medicina).

Las tres jóvenes declaran ser las primeras de sus respectivas familias (materna y paterna, o sólo paterna según el caso) en alcanzar el nivel superior de educación con continuidad de estudios desde el nivel secundario al terciario ${ }^{4}$. Al mismo tiempo, esto dota de un sentido aún más fuerte y significativo a su experiencia, ya que ésta se constituye en un referente para otros familiares, principalmente hermanos o primos menores. Por esto, el éxito o fracaso no sólo impacta en su propia vida, sino que también tiene efectos en otros significativos para las jóvenes. Esta condición de ser "la primera de la familia" connota de una responsabilidad distinta el paso por la ES, el que, sumado a la expectativa de los padres y a la pertenencia étnica de las familias, hace que las jóvenes sientan una fuerte responsabilidad respecto de su desempeño.

Lo anterior adquiere un valor de mayor significación si se considera la variable de género y clase, pues en sus relatos están presentes las dificultades que les ha implicado asumir y hacer propio el mandato paterno (en los casos de las jóvenes mapuche y aimara) y materno (en el caso rapa nui) de continuar los estudios postsecundarios y hacerlo en un nivel de excelencia, asociado a carreras de cierto prestigio social y centros universitarios tradicionales.

4 Ya que la madre y el padre que tienen nivel superior de educación, lo cursaron tiempo después de haber terminado la enseñanza secundaria, siendo estudiantes trabajadores. 


\section{Trayectoria escolar}

Todas las jóvenes señalan haber tenido una trayectoria escolar exitosa, traducida en un alto rendimiento y en obtener los primeros lugares de sus respectivas promociones. Esta trayectoria está marcada también por la búsqueda de los padres de situarlas en establecimientos educacionales que les permitieran una mejor formación, dentro de las posibilidades económicas de cada familia.

Salvo en el caso de la joven rapa nui, no se aprecia en la trayectoria escolar de estas jóvenes y, por tanto, en la motivación asociada el incentivo para desarrollar habilidades relacionadas con ámbitos distintos a los "intelectuales", como podría ser arte o deporte.

En general, la escuela o los ámbitos educativos aparecen como un espacio significativo pero no fundamental. Son un espacio de acogida pero también de situaciones ingratas. Con relación a esto, cada una de las jóvenes ha vivenciado situaciones de discriminación en diversos momentos de su historia educativa, los que han sido parte de su propia configuración, siendo resignificados por ellas. Si bien no es fácil llegar al reconocimiento de estas situaciones de discriminación (ya que generalmente en el relato aparecen como que sucede a otros, siendo difícil que las jóvenes expresen o se refieran a sus propias experiencias de discriminación), cuando éstas aparecen se presentan de modo similar y con un elemento común en las tres: están vinculadas con la ignorancia y el desconocimiento que tiene quien discrimina; por lo tanto, está asociada a quienes "no saben", a quienes no tienen niveles de formación suficiente para saber.

Cabe recordar que uno de los sentidos atribuidos a la educación en los discursos de las jóvenes es el de fuente de protección frente a las actitudes discriminatorias y racistas que pudiesen sufrir por su pertenencia étnica. Este sentido está instalado principalmente desde los padres aimara y mapuche, quienes las habrían preparado para hacer frente a dichas situaciones, constatando que la única forma de revertirlas era por medio de los estudios y del éxito en ellos. 
196 ESTUDIANTES UNIVERSITARIAS INDÍGENAS DE LA REGIÓN METROPOLITANA Carolina Maillard, Gloria Ochoa, Andrea Valdivia

\section{Experiencia universitaria}

Para las entrevistadas, la experiencia universitaria ha significado un reacomodo, una remirada desde distintas perspectivas. Por una parte, significa, al menos para dos de ellas (mapuche y aimara), dejar de ser las mejores, dejar de tener los primeros lugares y vivir la experiencia de la dificultad y del fracaso. Surge la pregunta respecto de las propias capacidades y de la decisión tomada. Cuando el ingreso ha sido por vía especial (la pertenencia étnica en este caso) la pregunta por las capacidades cobra más fuerza, ya que el ingreso no fue sólo por el puntaje obtenido; planteado de otra forma: con el puntaje obtenido no se estaría en la carrera que se cursa si no se perteneciera a determinado grupo étnico.

Por otro lado, para la joven rapa nui la experiencia universitaria ha significado un reforzamiento de su identidad étnica o del vínculo con su cultura. Ha facilitado el contacto con ésta y ha relevado o potenciado su vínculo. Además, por este reforzamiento, ella ha generado actividades en el presente que se relacionan con procurar mayores beneficios para la población rapa nui (como un preuniversitario), al mismo tiempo que ha nutrido sus expectativas de desarrollo profesional con un significativo compromiso con su pueblo.

Más allá de los cuestionamientos respecto de las capacidades que pudiesen sentir en ocasiones las jóvenes aimara y mapuche, ahora que están expuestas a procesos educativos de alta exigencia, las tres estudiantes comparten la claridad de que la identificación que los otros (en este caso el plantel universitario o el Estado en un sentido más alejado) hacen de ellas, en tanto indígenas, significa un reconocimiento positivo, y las lleva a plantearlo incluso como un factor promotor de sus sentidos de pertenencia. Todas las jóvenes evalúan positivamente la política de la universidad respecto de los pueblos originarios, ya que lo reconocen como un gran aporte y creen que estas iniciativas deberían mantenerse y multiplicarse, pero considerándose siempre, también, el rendimientos de los y las estudiantes que se acogen a ellas. 
Si bien tienen una valoración positiva acerca de las políticas de acción afirmativa en ES -dirigidas a favorecer el acceso de jóvenes indígenas con condiciones académicas adecuadas, pero que por sus condiciones económicas o de marginación no han accedido tradicionalmente-, también señalan que sólo son el primer paso del reconocimiento e identificación positiva de los indígenas. Por ejemplo, la joven aimara señala que estas acciones debieran ir junto por programas que, durante el proceso formativo, ofrezcan espacios de acompañamiento, desarrollo y encuentro entre los estudiantes indígenas; también, de instancias de diálogo, conocimiento y aprendizaje con estudiantes no indígenas.

\section{Expectativas de futuro}

Con relación a su futuro profesional y a las expectativas relacionadas, aún hay incertidumbres, ya sea por la propia capacidad de desarrollo o por el momento que viven las jóvenes. Es un espacio abierto porque puede significar trabajo o nuevos estudios, pero también porque no es el momento de pensar aún en el futuro. Y esto último está más presente en los discursos de las estudiantes aimara y mapuche, para quienes la experiencia universitaria ha adquirido un alto grado de exigencia y cuyos logros se han tornado más complejos. En el caso explícito de la primera joven, ella se repite constantemente que su meta, foco y prioridad es "sacar" su carrera. Sin embargo, entre las amplias expectativas está mejorar las condiciones de vida propias, de su familia y de las generaciones futuras.

Ahora bien, cuando las jóvenes se enfrentan a imaginarse el futuro, más allá del para qué de la formación universitaria, todas se mantienen en la dimensión profesional de sus vidas; las tres se ven trabajando en lo que estudian y continuando los estudios de posgrado o formándose en otras carreras vinculadas al área social, tales como pedagogía. Vale decir, trazan sus historias futuras en esa imagen de mujer profesional, inserta en el mundo laboral, pero con un sello distintivo otorgado por su autoidentificación étnica. Las tres manifiestan el deseo de vincular su quehacer profesional 
198 ESTUDIANTES UNIVERSITARIAS INDÍGENAS DE LA REGIÓN METROPOLITANA Carolina Maillard, Gloria Ochoa, Andrea Valdivia

con su cultura; entonces, la pertenencia étnica se convierte en un referente que otorga particularidad a sus respectivos desarrollos profesionales.

\section{Conclusiones}

El estudio buscaba indagar en la experiencia específica de jóvenes mujeres indígenas, estudiantes universitarias, con el fin de identificar pistas que ayudaran a configurar la dinámica, existente o no, entre ES y procesos de construcción de identidad étnica.

En el caso de las jóvenes participantes de este trabajo, existe una clara autoidentificación con las etnias (aimara, mapuche y rapa nui, según corresponda). Por lo tanto, la experiencia de ES no pareciera potenciarla ni tampoco disminuirla. Es decir, si bien no se evidencia un potenciamiento o fortalecimiento de esta autoidentificación, sí se aprecia que ser indígenas les permite mirar más positivamente la experiencia universitaria e, incluso, ver los beneficios asociados a ella.

Si bien las tres jóvenes comparten la autoidentificación con sus etnias, los grados de sentido de pertenencia varían según las experiencias vitales de cada una, en las cuales la discriminación (concreta o potencial), en especial hacia los aimara y mapuche, parece ser un factor que amenaza el sentimiento de pertenencia y afirmación. Es necesario destacar también cómo ciertas características de género son compartidas también por estas estudiantes; éstas se relacionan principalmente con el rasgo de "mujeres activas" que las tres ven en sí mismas: lo ocupadas y preocupadas que están de diferentes quehaceres, aunque su responsabilidad frente a los estudios sea la principal. Esta multiactividad y multifocalidad es una característica recurrente de lo que se podría llamar una "construcción actual del ser mujer" y que no es ajena a estas jóvenes.

En respuesta a lo anterior, la educación, en particular la universitaria, se visualiza como el gran factor protector frente a la 
amenaza. Dicho sentido, junto con el de movilidad social, atraviesan todo el discurso de las tres entrevistadas cuando argumentan respecto de la prioridad que tiene para ellas su formación profesional, en especial de las jóvenes aimara y mapuche. En los discursos de estas dos jóvenes está claramente la voz paterna que marcó sus trayectorias educativas, motivando e incentivando su destacado desempeño académico para mejorar sus expectativas de vida y responder o sobreponerse a la discriminación. En este sentido, un resultado llamativo de este estudio es constatar el rol que ejerce el padre en la trayectoria educativa de las jóvenes, así como en la motivación para que se superen a través de la educación, hecho que sería interesante indagar en otras investigaciones relativas a educación y estudiantes indígenas.

Por otro lado, este estudio también muestra las particularidades en las relaciones interculturales de nuestro país, asociadas a los grados de prejuicios étnicos y discriminación según el grupo indígena del que se trate. Claramente, la experiencia de la estudiante rapa nui muestra una identificación por parte del resto de la sociedad chilena y en particular en el espacio universitario, que si bien se construye sobre la base de estereotipos que folclorizan, no tiene la carga negativa que sí tienen los otros dos grupos indígenas. Esto, por cierto, potencia no sólo su sentido de pertenencia y autoidentificación, sino que, además, su actuar estratégico en la formación profesional y su proyección futura.

Las estudiantes valoran positivamente las políticas de acción afirmativa que favorecen su desarrollo educativo, como la beca indígena y los cupos especiales que ofrecen las instituciones de ES. Están conscientes de que sin estas políticas quizá no habrían ingresado a las carreras que hoy cursan; sin embargo, también son capaces de reconocer que esto es un gran desafío, y dudan en momentos que sean capaces de sortearlo. Por otro lado, también plantean la necesidad de que dichas políticas no sólo se centren en temas de acceso sino que también apunten al acompañamiento durante el proceso formativo, que se dirijan al encuentro y reconocimiento con otros estudiantes 
indígenas y no indígenas, con un sentido de comunidad similar al que ellas confieren como lo propio de sus culturas.

El estudio refleja entonces no sólo la diversidad cultural de nuestro país, sino también las variabilidades que al interior de los grupos reconocidos como minorías se presentan. Esto confirma el desafío de profundizar y atender seriamente su abordaje, toda vez que se asume su presencia en los contextos educativos actuales. Asimismo, evidencia que la identificación étnica y el reconocimiento de lo indígena por lo no indígena refuerzan el desafío que para estas estudiantes significan los estudios de nivel superior.

De esta forma, cuando relacionamos procesos de identificación étnica y ES se plantea un doble desafío para las instituciones que la imparten. Por un lado, facilitar y promover el acceso de los estudiantes indígenas, hombres y mujeres, a sus planteles; por otro, revisar las condiciones en que se desarrolla el proceso de formación, ya que el ingreso es una primera barrera que estos jóvenes han logrado salvar, pero la permanencia y sus características son también un acontecimiento significativo, porque apelan a su vivencia individual, pero también se relacionan con el colectivo al que pertenecen, ya que su experiencia es un referente para éste y es parte de la respuesta a la discriminación que han vivido los grupos indígenas en nuestra sociedad.

\section{Referencias bibliográficas}

Abarca, Geraldine y Zapata, Claudia (2007) Indígenas y Educación Superior en Chile: el caso mapuche. Calidad en la Educación, 26, pp. 57-79.

Arfuch, Leonor (comp.) (2005) Identidades, sujetos y subjetividades. Buenos Aires: Prometeo Libros.

Aguirre, Baztán (ed.) (1997) Etnografía. Metodología cualitativa en la investigación sociocultural. Barcelona: Alfaomega Marcombo, pp. 203-217.

Bello, Álvaro; Wilson, Angélica; González, Sergio y Marimán, Pablo (1997) Pueblos indígenas, educación y desarrollo. Chile: CEM, IEI Universidad de La Frontera, pp. 5-95. 
Bello, Álvaro y Rangel, Marta (2000) Etnicidad, raza y equidad en América Latina y el Caribe. CEPAL. (Sitio en Internet) Disponible en www.eclac.cl

Hopenhayn, Martín y Bello, Álvaro (2001) Discriminación étnico-racial y xenofobia en América Latina y el Caribe. CEPAL. (Sitio en Internet) Disponible en http//www.eclac.cl

INE y Programa Orígenes (MIDEPLAN / BID) (2005) Estadísticas Sociales de los pueblos indígenas en Chile, Censo 2002. Chile.

JUNAEB (2008) Condicionantes de género en deserción de beca indígena. Santiago de Chile (informe consultoría).

Larraín, Jorge (2001) Identidad chilena. Santiago de Chile: Editorial Lom.

Matus, Claudia (2004) El sujeto importado: complejidades, fragmentaciones y redefiniciones del estudiante internacional en universidades estadounidenses. Calidad de la educación, 21, pp. 288-301.

MIDEPLAN (2006) Encuesta de caracterización socioeconómica. Chile.

Papadópulos, Jorge y Radakovich, Rosario (UNESCO-IESALC) (2006) Educación Superior y Género en América Latina y el Caribe. (Sitio en Internet) Disponible en http//www.cse.cl Salazar, José Miguel (2005) Educación superior y género: Tendencias observadas. (Sitio en Internet) Disponible en http//www.cse.cl

Sebastián, Christian y Scharager, Judith (2007) Diversidad y educación superior. Algunas reflexiones iniciales. Calidad en la Educación, 26, pp. 19-36.

SERNAM (2002) Brechas de género en la educación superior en Chile. Algunos indicadores relevantes. Santiago de Chile.

Valenzuela, Rodrigo (2003) Inequidad, ciudadanía y pueblos indígenas. CEPAL. (Sitio en Internet) Disponible en htt/www.eclac.cl

Wacquant, J. (dir.) (2005) Repensar los Estados Unidos. Para una sociología del hiperpoder. Barcelona: Anthropos Editorial.

Recibido: 28 de abril de 2008

Aceptado: 27 de mayo de 2008 